\title{
Empowering International, Intersectoral and Interdisciplinary Dimensions in Higher Education: The STEPS and EECPS Master Courses Experience
}

\author{
Jorge Garcia*, Pablo Arboleya*, Cristina Gonzalez-Moran*, Pablo Garcia*, Marina Perdigao ${ }^{\dagger}$, Paulo Pereirinha ${ }^{\dagger},{ }^{* *}$ \\ Cristina Agreira ${ }^{\dagger}$, Fabio Giulii Capponi ${ }^{\ddagger}$, Giulio De Donato ${ }^{\ddagger}$, Alberto Castellazzi ${ }^{\S}$, Arthur Williams ${ }^{\S}$, \\ * Electrical Engineering Dept., University of Oviedo. Gijon, Spain, garciajorge@ uniovi.es \\ ${ }^{\dagger}$ ISEC, Coimbra Polytechnic ISEC, Coimbra, Portugal \\ ** INESC Coimbra, Coimbra Portugal \\ $\ddagger$ DIAEE, University of Rome-La Sapienza, Roma, Italy \\ $\S$ Dept. of Electrical and Electronic Engineering, The University of Nottingham, Nottingham, UK
}

\begin{abstract}
This work shows the experiences gone through in the implementation of the academic syllabus of two Higher Education Master Courses, the Electrical Energy Conversion and Power Systems (EECPS) Master Degree, and the Erasmus Mundus Joint Master Degree in Sustainable Transportation and Power Systems (EJMJD STEPS). Both titles cover specifically the competences and learning results required for professionals on leading edge technologies at the electrical transportation sector. This work will show the procedure from the early concepts of the degree, the design of the contents of the subjects and modules, the schedule of these subjects in the curriculum, the evaluation and methodologies, up to the continuous quality monitoring procedures implemented to ensure an adequate development of the course.
\end{abstract}

Index Terms-Master Degree, Erasmus Mundus, Sustainable Transportation, Power Systems, Electrical Energy Conversion.

\section{INTRODUCTION}

Transport and energy sectors are two of the most important areas for the economic development of a region. The European Commission recognized these two sectors as key ones in order to guarantee a sustainable future for the whole world and to improve the quality of life of its inhabitants [1]. The European Commission energy strategy aims to make the use energy, including transportation, more affordable, secure and sustainable [2]. But both sectors are undergoing a technological revolution in the present years [3].

In the case of the energy sector, and in particular when considering power systems, the outbreaking and integration of new technologies will change in few years the electrical energy generation and distribution paradigm [4]. This

This work has been partially supported by: the EACEA, Education, Audiovisual and Culture Executive Agency from the European Commission, under Erasmus + Programme, Grant No. 574442-EPP-1-2016-1-ESEPPKA1-JMD-MOB, EMJMD STEPS; the Government of the Principality of Asturias, Spain, under Grant No. FC-GRUPIN-IDI/2018/000241; and by FCT Portuguese Foundation for Science and Technology under Project UID/MULTI/00308/2019. paradigm will switch from a conventional purely centralized system to a hybrid distributed/centralized system, in which large and efficient power plants will coexist with all kind of sizes distributed generators and storage subsystems, and many of them based on renewable technologies [5]. A large penetration of these distributed resources into the system is only possible ensuring a correct coordination between these resources, therefore requiring a flexible, versatile power system scheme [6]. For this purpose, the development of power electronic applications in order to interface the distributed resources with the power systems is vital, together with the development of hybrid distributed/centralized controls that are able to provide an appropriate coordination to the whole network, in microgrids, smartgrids or smartcities [7]. New concepts like energy aggregators, prosumers, demand response or transactive energy will change totally the current power system landscape [8]. The development of applications based on Internet of Things and the development of peer to peer energy transaction systems, for instance based on blockchain or similar technologies, will create new power system roles and new ways of planning, deploy and operate the power systems [9], [10].

In the case of the transportation sector, the obvious revolution has to do with the massive irruption of the electric vehicles and the transportation electrification schemes [11], [12]. Electric transportation must be understood not only referring to the electric vehicle itself, but also to a wide range of applications that share the common feature of using electricity for traction and related purposes. In this category, conventional electric vehicles must be considered, off course, but also railway applications, the more electric aircrafts, the more electric ships, and even small e-mobility solutions, such as scooters or bikes [13], [14]. Electrification in the transport sector is reaching every single way of transport. 
Therefore, it is critical to incorporate higher education training programs that include all these new disruptive technologies, aiming to reflect the drastic change in the ongoing power systems and transportation sectors [15], [16]. This work can be understood as a summary report on the experiences of the steering committees of two Higher Education Master Courses, the Electrical Energy Conversion and Power Systems (EECPS) Master Degree, and the Erasmus Mundus Joint Master Degree in Sustainable Transportation and Power Systems (EJMJD STEPS). The contents, topics, syllabus and schedule of both courses are very similar; the former is an official title issued by the University of Oviedo (Spain), while the latter is a joint degree, recognized and steered jointly by the four institutions in the consortium. Besides the University of Oviedo, the consortium is formed by The University of Nottingham (UK), The University of Rome-La Sapienza (Italy) and the Politechnical Institute of Coimbra (Portugal).

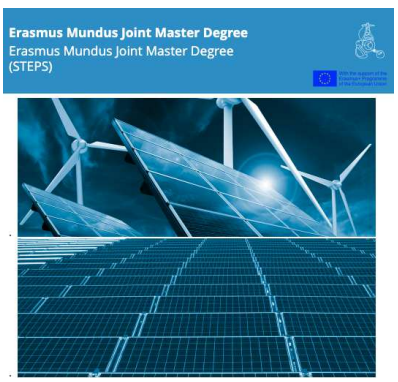

Fig. 1. Website frontpage of the EJMJD STEPS degree.

Both degrees are 120 ECTS courses, accounting for 2 years full time. The degrees are taught fully in English language, with a string participation of external faculty from engineering and market operation companies. All students carry out practice internships in companies or external universities during the fourth semester, usually binded to their Master Thesis.

The work is scheduled as follows. In first place, a short introduction on the consortium is presented, stressing the relations of the members with technical and industrial partners that are key for the success of the programme. The following sections describe how the competencies and learning objectives of the degrees are targeted. The syllabus of the subjects and modules are not described in detail in this work. They can be found at the official Websites of both degrees [17], [18]; instead, the basic learning outcomes of the programme are discussed. Lastly, some conclusions are presented.

\section{The STEERING CONSORTIUM}

The STEPS partners institutions and the departments directly involved in the JMD have a long tradition of cooperation with non-educational actors:

- The University of Oviedo Department of Electrical, Electronics, Computers and Systems (DIEECS), is one of the University leading departments by the number of contracts and joint projects with industry. Some of the faculty members are actively involved in partnership with regional, national and international leading companies (EdP, Arcelor-Mittal, Alstom Transport, TSK, Cegasa
P. E., Siemens-Gamesa, Iberdrola Renovable, Schneider Electric, Ford Motor Company, CAF TE).

- The University of Nottingham Faculty of Electrical Engineering has very strong links with industry, both nationally and internationally, in different fields, through the involvement of research groups such as PEMC. Research areas are funded by both public and private entities: EPSRC/GE Aviation, US Army Research Labs, TSB, Airbus, Boeing and Innovative electronics Manufacturing Research Centre Awards. In Energy, the Group has a growing portfolio including SUPERGEN Networks Hub, Energy Networks Grand Challenge, converters for distribution grids (UNIFLEX, CEMEP), converters for direct wind generators (Converteam/TSB) and intelligent power system condition monitoring (MOD, Qinetiq, Alstom).

- The Sapienza-University of Rome Department of Astronautical, Electric and Energetic Engineering (DIAEE) has an important portfolio of projects in cooperation with industrial partners. Finmeccanica, CIRA, ENEL, Terna, ACEA, Hitachi Rail Italy, Rete Ferroviaria Italiana and Elettromeccanica Lucchi are among the main industrial partners. Sapienza University of Rome is one of the oldest universities in the world and a high performer among the largest universities in international rankings. It is ranked first amongst Italian universities (ARWU Academic Ranking of World Universities, U.S. News), while, according to QS (Quacquarelli Symonds), it ranks number 213 globally.

- The Polytechnic Institute of Coimbra (IPC) Department of Electrical Engineering (DEE), has participated in more than 35 European and Portuguese research and development projects, most of them in cooperation with Portuguese and international companies, and other R\&D institutions. REN - Redes Energéticas Nacionais SA, Critical Software, Active Space Technologies, DKM Control, MAHLE, Martifer, Minimenergy, Olympus, Optieng, and Sramport are among the Department key partners.

The EECPS Master degree is coordinated by the university of Oviedo, yet with significant contributions from the rest of the members of the consortium.

\section{Analysis of Major NeEdS In EleCtriC ENGINEERING}

Mastering energy has been the main driver of modern growth and development. Now, the world faces several energy challenges very closely interrelated: to reduce the energy intensity and improve energy efficiency; replace fossil by renewable energy sources to cut down $\mathrm{CO}_{2}$ emissions; key changes in energy production and consumption patterns, and use technology to develop a smarter energy model. The EU is in the forefront of the transformation of Europe's and World's electricity production. Today, more than half of Europe's electricity supply is free from greenhouse gas emissions. The EU currently hosts 6 of the 25 largest renewable energy businesses and employs almost 1.5 million people (out of 10 million worldwide). The global expansion of renewable 
energy has led to massive cost decreases in the last 10 years, in particular in solar and on- and off-shore wind. The following are the energy sectors more involved in this transformation.

\section{A. Renewable Energies and Power Systems.}

The development of renewable energies, both in Europe and worldwide, is still constrained by challenges in production, storage, transmission and distribution challenges, and needs new technology breakthroughs. The transition towards a largely decentralised power system based on renewables will require a smarter and flexible system, building on consumers' involvement, increased interconnectivity, improved energy storage deployed on a large scale, demand side response and management through digitalisation [19]. Integration of renewable energy sources (RES) in the existing power systems is leading the electrical energy sector in the following areas:

- Generation. Efficiency and reliability are the key points receiving attention.

- Transmission. High Voltage Direct Link (HVDC) and Flexible AC Transmission Systems (FACTS).

- Distribution. Introduction of Renewable Energy Systems (RES) require new optimization methods for energy dispatch, which take into consideration interconnection standards and operational constraints.

\section{B. Challenges in Sustainable Transportation.}

Transport is responsible for around one-third of total final energy consumption globally, and a quarter of greenhouse gas emissions in the EU. With a system-based approach, the combination of decarbonised, decentralised and digitalised power, more efficient and sustainable batteries, highly efficient electric powertrains, connectivity and autonomous driving offers prospects to decarbonise the mobility system with strong overall benefits. This should be coupled with a more efficient organisation of the entire mobility system based on digitalisation, data sharing and interoperable standards to make mobility cleaner [19]. The generalisation of full electric and hybrid electric vehicles will also require of substantial investments in research and development in the following areas:

- Energy storage. Augmented power density in the energy storage systems, including development of batteries and fuel cells.

- Energy conversion. Traction force is generated throughout several power conversion stages.

- Traction machines. For full electric and hybrid vehicles, electrical machines design and control strategies for maximum torque per ampere production, increased reliability and robustness when a fault occurs are needed.

- Grid integration. Significant improvements and changes in the power grid management are key when integrating the Charging Stations, such as smart grids, V2G, etc.

\section{The challenges and opportunities of digitalisation.}

Digital technologies have been used in the energy sector for decades, but in recent years their application has expanded rapidly. The ongoing digital transformation of energy has the potential to bring more efficiency, flexibility and co-ordination to the management of energy end-use sectors and across the entire system, with the added benefit of advancing the integration and further deployment of renewable energy. Digitalisation is rapidly and fundamentally changing the way in which energy is produced and consumed. On the supply side, the use of sensors and analytics is helping to reduce operation and maintenance costs and plant outages, and is improving power plant and network efficiencies. On the demand side, vehicles are becoming smarter and more connected, energy efficiency in buildings is increasing, and process controls, smart sensors and data analytics are contributing to costeffective energy savings in industry [20].

\section{Human Capital Needs and Job Opportunities.}

Different reports highlight the job creation potential of RES and sustainable transportation sectors worldwide, and more specifically in the EU. Energy transition will increase employment in the broader economy, but also in the energy sector and in renewable energy. By 2016, energy sector employed 1.6 million people (41 million people Worldwide). Employment in the renewable energy sector in the EU has boomed in the last decade, increasing from 200,000 jobs in 2004 to nearly 1.3 million in 2016 (8.8 million worldwide), and the EU Commission estimates that employment in power generation may increase up to $22.3 \%$ by 2050 (reaching 28.8 million worldwide) [19].

There is broad agreement that the loss of fossil fuel jobs will be largely offset by the number of jobs created in renewable energy technologies, as the higher labour intensity of renewable energy technologies (more jobs per MW of power installed, per unit of energy produced, and per EUR of investment) has a positive impact on employment, and investments in energy efficiency measures and grid enhancement create further employment opportunities. RES and electric mobility are therefore among the most promising sectors in terms of social return, job creation and relevance to the global economy. Renewables create jobs with a wide range of occupational and skills requirements, from workers and technicians to highly qualified field and planning engineers and researchers. Some calculations indicate that about $30 \%$ of jobs require at least tertiary education, and half of them would need postgraduate education [21].

Responding to all of these challenges requires professionals with solid and updated skills. Energy and electric mobility sectors grow even in a context of economic crisis, and require well-trained professionals. Many sector studies indicate that these sectors are already facing the lack of engineers acquainted with the latest technological developments. Eurostat estimations indicate that about 585,000 students graduated in 2016 in engineering, manufacturing and construction higher education programmes (ISCED 6-8: BSc, MSc and $\mathrm{PhD}$ ), slightly higher than the previous year. However, they are only $14 \%$ of total graduates; furthermore, graduates in ISCED 6-8 electricity and energy programmes were just 34,000 in 2016, less than $1 \%$ of the total graduates [22]. 


\section{Programme Competences And Learning Results.}

The EECPS and STEPS programmes provide graduates with the academic and practical skills required to meet the aforementioned needs. Within the identified key areas, the approach and contents of the Master programmes respond to the following challenges faced by the energy sector:

- To master new energy sources and their implications on the power grids;

- To reduce $\mathrm{CO}_{2}$ emissions by increasing energy efficiency and the share of clean energies;

- To gradually incorporate electrical transportation as an alternative to internal combustion engine (ICE) vehicles.

The academic programmes have been designed to address such challenges. Using a holistic methodology, the programmes offer an integrated and specialized approach to tackle some of the key issues in this field:

- Management of generation technologies, in particular renewable energy sources;

- Grid connection interfaces including electronic power converters and control systems;

- Technologies for energy storage systems;

- Transport and distribution systems, including smart grids and micro grid concepts;

- Use and impact of digital technologies for the management of power generation, distribution and consumption;

- Impact of electrical transportation systems (EV/HEV) on the electrical network;

- Power electronics applications for EV/HEV;

The programme emphasizes both the industrial and the scientific dimension, and prepares students either for a job in industry via internships in world leading companies or towards academic and research career. The programmes also provides full personal and academic support to students through the individual Students Mentoring Programme, with each student being supported by one of the Master Professors for the learning process and career planning. The programme also offers students the opportunity to attend local language and local culture courses to facilitate their integration in the mobility countries. In the case of STEPS students, they will be studying in at least $3 \mathrm{EU}$ countries. The programme also offers the opportunity of carrying out the internship and the preparation of the Master Thesis in a fourth different country, eventually also outside the EU (in North, South America and Asia). In the case of EECPS students, that is fully taught at the University of Oviedo (Spain), the mobility is encouraged, yet not mandatory, in the internship during the 4th semester. The Master programmes are supported by leading energy related companies (power generation and distribution, renewable energy companies, manufacturers of energy equipment, automotive companies...). Companies are both financially and academically committed to the programmes: all of them will offer paid internships; they will collaborate in teaching, depending on Master needs and availability, and may be offering scholarships. The EECPS and STEPS JMD are increasingly gaining the recognition and support of the private sector.

\section{The PROGRAMME}

Both programmes consists of four terms distributed in two years. The first term is intended to provide a uniform level of knowledge among students with different basic training. This equalization term offers a set of optional courses designed to promote the homogenization among students' knowledge. The teaching committee will study every application form independently, selecting 30 ECTS credits for every student among the optional courses. The second term offers several compulsory courses for all the students. These subjects will promote the acquisition of the common skills of the Master. The third term has been designed according to two possible tracks: power systems and sustainable transportation. The last term has been designed to complete the training of students. The courses taught in this period have a general nature and address issues related to the socio-economic impact of the technologies studied in the Master. In addition, students have to complete their Master's Thesis and the internship.

The learning outcomes have been set to meet the needs identified previously and can be classified attending to their scope, considering basic or particular topics covered by the master. The following states the relevant learning outcomes. Among the basic learning outcomes, key competences related to transferable and soft skills, such as the capacity of managing information, the self-learning skills, the ability to work within a research or technical team, the concern for quality, ethics and accomplishment will be covered in the degree. Also, special attention will be paid to the following learning outcomes, depending on the selected track.

\section{A. Electrical Power Systems (Generation, Transmission and Distribution of Electrical Energy)}

- Understanding of the importance and the area of utilization of electrical power systems for generation, transmission and distribution of electrical energy.

- Identification of the main characteristics, design strategies and the constructive elements and materials of the Electrical Power Systems.

- Ability to understand the basics of the dynamic modelling of electrical power systems.

- Understanding the relevance of the control systems and monitoring in electrical power systems.

- Acquire the basic knowledge of power electronics to analyse and design electrical power systems.

- Ability to analyse the different strategies for grid connection, for both technical and economic points of view.

- Knowledge of the relationships between different electrical markets, as well as the regulation of activities involved in the management of primary energies.

- Ability to understand, analyse and discuss the main macroeconomic variables involved in the energy sector.

- Ability to identify and classify the main aspects and business strategies related to investments, financing, risk management and fiscal policy in the energy markets. 
TABLE I

- Knowledge of the marketing mechanisms among the elements of the energy markets, particularizing for the electrical energy market.

\section{B. Sustainable Transportation (Electrical \& Hybrid Vehicles)}

- Understanding the fundamental characteristics, as well as advantages and drawbacks of electrical and hybrid traction systems compared to combustion engines.

- Acquire the knowledge of power electronics needed to analyse and design electrical and hybrid traction systems.

- Ability to understand the importance and particular issues of the control and monitoring systems used in electrical and hybrid traction systems.

- Ability to understand the need for energy storage systems and control strategies in electrical and hybrid vehicles.

- Ability of understanding the concepts, strategies and power transmission systems involved in the design of the electrical and hybrid vehicle.

- Understanding of the mechanical background necessary to integrate the electrical and mechanical power subsystems in a hybrid/electrical vehicle.

- Ability to analyse and understand electric drives design.

- Ability to assess the environmental and social implications of the operation of the sustainable transportation systems including sustainable development concerns.

The achievement of these learning outcomes are ensured through a variety of learning methodologies, that include project based learning, hands-on practice in laboratory setups, writing of technical reports, presentation of the reports to the group, discussion and defense of the works and projects.

\section{The Students}

The STEPS Consortium has been successfully attracting talented students from different parts of the world, particularly from Asia, Africa, Latin America, the South Mediterranean countries and Central Asia. Altogether, more than $90 \%$ of the applications in the eight editions of the Master have come from those areas, particularly from Asia. Nearly 55\% of applicants come from Asia, especially from Pakistan (almost $25 \%$ of all applications), Bangladesh, India, China and Nepal (almost another 25\%). Applicants from Africa are growing in the JMD editions, as well as those from Latin America and Central Asia. The STEPS communication strategy is targeting these areas through the different marketing channels, but specially through an active web promotion, including social networks, which are particularly effective to reach Asian applicants. About alumni, the number of students graduated form the STEPS Master is currently 68, from 34 different countries worldwide. Table VII states the nationality of STEPS Alumni, while Fig. 2 shows these nationalities grouped by continent. It must be noticed that from an operative point of view, the effect of such a high diversity in the nationalities of the students has a positive impact in the learning process of key soft skills such as teamwork, communication skills, social abilities and respect for diversity. On the other hand, the huge span of the incoming BSc. degree structures turns the teaching process
MAIN NATIONALITIES OF STEPS ALUMNI

\begin{tabular}{|r|r|r|r|r|l|}
\hline India & 7 & Nigeria & 3 & China & 2 \\
\hline Pakistan & 6 & Eritrea & 3 & Turkey & 2 \\
\hline Ethiopia & 5 & Iran & 3 & Serbia \& Mon. & 2 \\
\hline Bangladesh & 5 & Jordan & 2 & $\begin{array}{r}\text { Rest of } \\
\text { Countries* }\end{array}$ & 23 \\
\hline Spain & 3 & Nepal & 2 & Coun
\end{tabular}

*Sri Lanka, Greece, Mexico, Romania, Czech Republic, Tunisia, Latvia, Indonesia, Ukraine, Malawi, Thailand, Bosnia \& Herzegovina, Ecuador, Venezuela, Vietnam, Honduras,

Colombia, Egypt, Yemen, Tajikistan, Italy and Saudi Arabia.

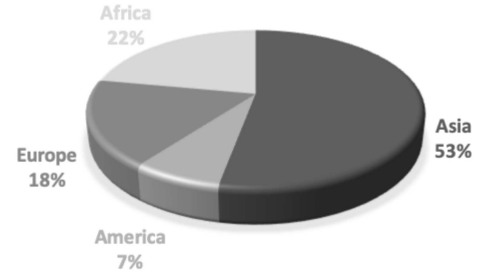

Fig. 2. Main nationalities of STEPS Alumni grouped by Continent

very demanding, specially in the first semesters of the degree. However, the specific mentoring programme implemented in the degree is designed to detect any potential learning issue and to correct it with enough time in advance. The figures are similar in the case of the EECPS Master degree (currently around 80 alumni since the first edition in 2011). However, in terms of the nationality of students, in this case the vast majority, around $75 \%$, are Spanish students, being also 5\% of them from other EU countries, while the remaining $20 \%$ come from outside the EHEA (Mainly Egypt, Turkey and Latin American countries).

\section{A. Gender aspects}

Positive discrimination measures will be applied to increase the number of women and of underrepresented groups to be called for interview. The justification of these measurements is explained ahead for the case of gender balance. Table II shows the number of applications received in the former STEPS cohorts, considering the gender of the applicants. As it can be seen, on average around $10 \%-15 \%$ of applications are submitted by women. In order to balance the gender of alumni in the long term, the better ranked women per country are sent to the interview process independently of their individual ranks. Also Table II shows the number of alumni finishing the STEPS degree and its gender. It can be seen how since these positive discrimination measures were introduced (from cohort 2016-18 onwards), the $\%$ of women raised up to $33 \%$, achieving a more balanced gender distribution.

TABLE II

Gender of STEPS Alumni Gender of STEPS APPLICANTS

\begin{tabular}{|c|c|c|c|c|c|c|}
\hline Cohort & Men & Women & $\%$ of Women & Men & Women & $\%$ of Women \\
\hline $2012-14$ & 12 & 2 & $14,29 \%$ & 302 & 26 & $7,93 \%$ \\
\hline $2013-15$ & 16 & 1 & $5,88 \%$ & 217 & 37 & $14,57 \%$ \\
\hline $2014-16$ & 10 & 2 & $16,67 \%$ & 226 & 41 & $15,36 \%$ \\
\hline $2015-17$ & 11 & 1 & $8,33 \%$ & 207 & 34 & $14,11 \%$ \\
\hline $2016-18$ & 10 & 5 & $33,33 \%$ & 282 & 34 & $10,76 \%$ \\
\hline $2017-19$ & 10 & 5 & $33,33 \%$ & 254 & 37 & $12,71 \%$ \\
\hline
\end{tabular}

\section{IMPLEMENTATION AND SUCCESS INDICATORS}

The interaction with industry representatives will enhance the students knowledge on industry situation and needs. The 
evaluations carried out on the STEPS course and the feedback from graduates show that the Master has been instrumental to improve the employability of graduates, and to start or boost a successful professional career, either in industry or in academia. So far, the Master has been very successful; nearly $95 \%$ of the graduates are employed, many of them in industrial multinational companies or in research institutions. In some cases, graduates were employed immediately after graduation, often in the company where they carried out the internships, or as a researchers and $\mathrm{PhD}$ candidates in partner or associate Universities. The information available on the three first cohorts of the STEPS degree show a balanced insertion in industry and academia. Most of graduates employed in industry have been employed by large multinational companies, which have appreciated the transnational component of the Master as a major advantage. The information provided by the Alumni shows the usefulness of both the technical and the transversal competences provided by the Master. The positions accessed by the graduates are already helping to enlarge the Master network, to attract new students and, in particular, to attract new associated partners and eventually to attract funding for new scholarships for students to attend the Master.

As for the EECPS Master, the rate of labour insertion of its students is of $90 \%$ within 3 months of completion, and practically $100 \%$ within 1 year. Approximately half of the students find a position in companies in the sector, while the other half is dedicated to studying the doctorate in the research area of the Master's lines, in different national and international academic institutions.

\section{CONCLUSIONS}

The EECPS and STEPS programmes have been analyzed, from the point of view of how to design learning outcomes and competences to acquire based on the demands from the industry and the whole society. It has been demonstrated how both programmes pay a particular attention to multicultural learning, which has become a key feature in the globalized engineering work. The master graduates will be achieving the following educational objectives and qualifications:

- Academic qualification: ability for scientific work, research and assessment.

- Qualification to be a competent engineer: ability to transfer skills and to use the best methodology for efficient product development.

- Adaptability and flexibility: ability to adapt quickly to deal with various tasks and problems.

- Professional qualification and management qualification: ability for interdisciplinary cooperation (team work).

- Qualification in intercultural communication: ability to communicate easily with people from different countries in different languages.

\section{REFERENCES}

[1] "European commission climate strategies and targets, 2030 climate and energy framework." https://ec.europa.eu/clima/policies/strategies/2030en.
[2] "European commission science hub. energy and transport science area. https://ec.europa.eu/jrc/en/science-area/energy-and-transport."

[3] A. El-Refaie, "Toward a sustainable more electrified future: The role of electrical machines and drives"," IEEE Electrification Magazine, vol. 7, no. 1, pp. 49-59, March 2019.

[4] G. S. et Al., "Cost-effective decarbonization in a decentralized market: The benefits of using flexible technologies and resources," in IEEE Power and Energy Magazine, vol. 17, no. 2, pp. 25-36, March-April 2019.

[5] L. Barroso and H. Rudnick, "The future power system: Centralized, distributed, or just integrated? [guest editorial]," IEEE Power and Energy Magazine, vol. 17, no. 2, pp. 10-14, March-April 2019.

[6] M. O’Malley and B. Kroposki, "Unlocking flexibility: Energy systems integration [guest editorial]," IEEE Power and Energy Magazine, vol. 15, no. 1, pp. 10-14, Jan.-Feb. 2017.

[7] V. Smil, "Distributed generation and megacities: Are renewables the answer?" IEEE Power and Energy Magazine, vol. 17, no. 2, pp. 37-41, March-April 2019.

[8] T. Mai, D. Steinberg, J. Logan, D. Bielen, K. Eurek, and C. McMillan, "An electrified future: Initial scenarios and future research for u.s. energy and electricity systems," IEEE Power and Energy Magazine, vol. 16, no. 4, pp. 34-47, July-Aug. 2018.

[9] P. Frankl, "Energy system debate: What lies ahead for the future [in my view]," IEEE Power and Energy Magazine, vol. 17, no. 2, pp. 100-98, March-April 2019.

[10] G. Cho, C. Kim, Y. Oh, M. Kim, and J. Kim, "Planning for the future: Optimization-based distribution planning strategies for integrating distributed energy resources," IEEE Power and Energy Magazine, vol. 16, no. 6, pp. 77-87, Nov.-Dec. 2018.

[11] F. R. Soriano, J. J. Samper-Zapater, J. J. Martinez-Dura, R. V. CiriloGimeno, and J. M. Plume, "Smart mobility trends: Open data and other tools," IEEE Intelligent Transportation Systems Magazine, vol. 10, no. 2, pp. 6-16, Summer 2018.

[12] P. G. Pereirinha, M. Gonzlez, I. Carrilero, D. Ansen, J. Alonso, and J. C. Viera, "Main trends and challenges in road transportation electrification," Transportation Research Procedia, vol. 33, pp. 235 - 242, 2018, xIII Conference on Transport Engineering, CIT2018. [Online]. Available: http://www.sciencedirect.com/science/article/pii/S2352146518302527

[13] P. Ladoux, "Electrical systems for air, land, and sea travel and the international transportation electrification conference [newsfeed]," IEEE Electrification Magazine, vol. 5, no. 1, pp. 71-71, March 2017.

[14] R. Palacin, "Hyperloop, the electrification of mobility, and the future of rail travel [viewpoint]," IEEE Electrification Magazine, vol. 4, no. 3, pp. 4-51, Sept. 2016.

[15] D. Ray, N. R. Chaudhuri, and S. Brahma, "Trends in electric power engineering education: An analysis of future challenges," IEEE Power and Energy Magazine, vol. 16, no. 5, pp. 32-41, Sept.-Oct. 2018.

[16] I. Power and n. . p. .-. S.-O. . Energy Magazine, vol. 16, "Electric power engineering education: Cultivating the talent in the united kingdom and italy to build the low-carbon economy of the future," $G$. Chicco and P. Crossley and C. A. Nucci.

[17] "https://mastereecps.uniovi.es/," 2018.

[18] "http://www.emmcsteps.eu/," 2018.

[19] "A clean planet for all - a european strategic long-term vision for a prosperous, modern, competitive and climate neutral economy." $E U$ Commission Communication, vol. COM(2018), p. 773, 2018.

[20] A. Zervos and R. Adib, "Ren21 renewables 2018 global status report." Renewable Energy Policy Network for the 21st century, 2018.

[21] "Renewable energy and jobs. annual review," IRENA 2018, 2018.

[22] "Distribution of graduates at education level and programme orientation by sex and field of education," Eurostat, 2018. 